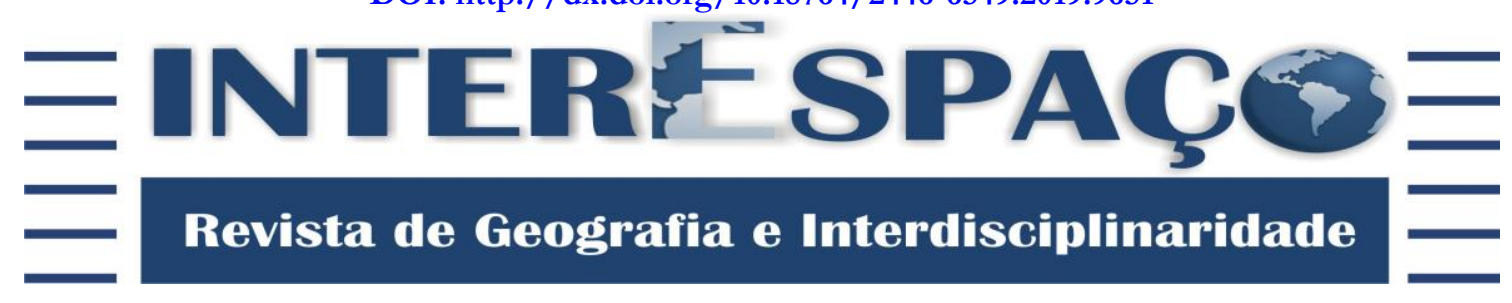

\title{
CONSTRUÇÃO DA AUTONOMIA NA EDUCAÇÃO INFANTIL: interações entre crianças e professoras
}

\section{CONSTRUCTION OF AUTONOMY IN EARLY CHILDHOOD EDUCATION: interactions between children and teachers}

\section{CONSTRUCCIÓN DE AUTONOMÍA EN LA EDUCACIÓN INFANTIL: interacciones entre los niños y los maestros}

\author{
Maria Fabrícia de Medeiros \\ Doutora e Mestra em Educação pela Universidade Federal da Paraíba - UFPB. Professora Efetiva \\ da Prefeitura Municipal de João Pessoa-PB. \\ fabriciamedeiros@hotmail.com / http://orcid.org/0000-0002-1926-4618
}

Adelaide Alves Dias

Doutora em Educação pela Universidade Federal Fluminense - UFF e Pós-doutora em Educação pela Universidade do Estado do Rio de Janeiro - UERJ. Professora Titular aposentada da Universidade Federal da Paraíba - UFPB e Professora Visitante da Universidade do Estado do Rio Grande do Norte - UERN. adelaide.ufpb@gmail.com / http://orcid.org/0000-0002-3989-9338

Recebido para avaliação em 02/09/2018; Aceito para publicação em 06/11/2018.

\section{RESUMO}

Este estudo investigou as interações e afetividade entre professoras-criança e criança-criança e suas implicações para o processo da autonomia infantil. Observou-se a rotina diária de uma turma de Maternal 2 com 26 crianças de 3 anos, uma professora e uma monitora em um CREI-Centro de Referência em Educação Infantil na cidade de João Pessoa-PB. A técnica empregada foi a de vídeogravação de episódios interativos e os dados foram tratados por meio da análise microgenética, onde dividimos os episódios interativos em 3 (três) tipos de díades: criança-criança, professoras-criança e criança-professoras. Os resultados indicam que as crianças resistiam e construíam sua autonomia entre os pares. É oportuno dizer que encontramos um ambiente com interações intercaladas entre afetivas e proporcionadoras da construção da autonomia (criançacriança) e outras disciplinadoras (professora ou monitora-criança).

Palavras-chave: Autonomia; Interações; Afetividade.

\section{ABSTRACT}

This study investigated the interactions and affection between child teachers and child-child and its implications for the process of children's autonomy. There was the daily routine of a group of Maternal 2 with 26 children 3 years old, a teacher and a monitor in a Children's Education Reference CREI-Center in the city of João Pessoa-PB. The technique used was the video recording of interactive episodes and the data were treated by microgenetic analysis, where we divided the interactive episodes in three (3) types of dyads: child-child, child-teachers and child- teachers. The results indicate that children resisted and building their autonomy among peers. It is fair to say that we find an environment with interactions interspersed between affective and proporcionadoras the construction of autonomy (child-child) and other disciplinary (teacher or monitor-child).

Keywords: Autonomy; Interactions; Affectivity. 
| Maria Fabrícia de Medeiros | Adelaide Alves Dias |

\section{RESUMEN}

Este estudio investigó las interacciones entre maestros y afecto y cuidado de los niños y sus implicaciones para el proceso de autonomía de los niños. No era la rutina diaria de un grupo de Maternal 2 con 26 niños de 3 años, un profesor y un monitor de referencia Educación CREI centro de niños en la ciudad de João Pessoa -PB. La técnica utilizada fue la grabación en vídeo de episodios interactivos y los datos fueron tratados mediante análisis microgenético, donde se dividió a los episodios interactivos en tres (3) tipos de díadas: Familias con niños, Apto para maestros y niños-profesores. Los resultados indican que los niños se resistieron y la construcción de su autonomía entre pares. Es justo decir que nos encontramos con un entorno con interacciones intercalados entre afectiva y proporcionadoras la construcción de la autonomía (el niño-niño) y otra disciplina (profesor o monitor-niño).

Palabras clave: La Autonomía; Interacciones; La Afectividad.

\section{INTRODUÇÃO}

Este artigo objetivou analisar as interações e afetividade cotidianas entre professoras-criança e criança-criança e suas implicações para a construção da autonomia infantil no contexto de um Centro de Referência em Educação Infantil-CREI na cidade de João Pessoa - PB. Partimos do princípio de que a dimensão da afetividade é central tanto para a construção da pessoa, quanto para construção do conhecimento através do contato direto e constante com o meio social através das relações interativas com outras pessoas. Conforme afirma Wallon (2007, p. 115), “à afetividade concernem, ao que tudo indica, as manifestações psíquicas mais precoces da criança. Ela está ligada desde o início a suas necessidades e automatismos alimentares, que são praticamente consecutivos ao nascimento". Assim sendo, a afetividade é inata ao ser humano, a forma mais primitiva do desenvolvimento, manifestada desde o nascimento e vai tomando outras formas e proporções à medida que as fases de desenvolvimento vão sendo superadas. Nesse sentido, Dias et al. (2012, p. 192) confirmam, portanto, que:

É importante pensar a afetividade, que é um campo abrangente constituído pelas emoções, sentimentos e paixões, como um aspecto tão importante quanto a própria inteligência e que, como esta, encontra-se presente no ser humano. A afetividade deve ser entendida como elo entre a vida orgânica e a psíquica.

Ante disso, ressaltamos que a afetividade é elementar a todo ser humano, sendo esta, central, tanto para "a construção da pessoa, quanto para a construção do conhecimento" (DIAS et al., 2012, p. 192). Dessa forma, "é inevitável que as influências afetivas que rodeiam a criança desde o berço tenham sobre sua evolução mental uma ação determinante" (WALLON, 2007, p. 122). E, assim sendo, refletimos sobre a importância não apenas da afetividade propriamente dita para o desenvolvimento da criança, mas 
estamos tratando diretamente das interações afetivas que acontecem durante toda a vida e que afetarão decisivamente não apenas o desenvolvimento, mas também a formação como pessoa e a construção da autonomia.

Na perspectiva de De La Taille (2006, p. 17), as motivações humanas, entre elas as morais, não podem ser tratadas sem a teoria da afetividade, lembrando que "a moral pressupõe conservação de valores e não somente investimentos afetivos passageiros... considerou a hipótese de que o rumo do desenvolvimento moral é o da autonomia”. Diante do que foi colocado, podemos inferir que a afetividade é um dos pressupostos para a estruturação do desenvolvimento moral que por sua vez está à construção da autonomia.

Nessa direção, é a partir das interações com o mundo que se constroem possibilidades das crianças estruturarem bases para desenvolver sua autonomia e assim participar ativamente do meio social, refletindo, questionando e avaliando suas ações e consequências que estas lhe trarão, é neste contexto que este trabalho se insere.

\section{O PAPEL DAS INTERAÇÕES ENTRE PROFESSOR-CRIANÇA E CRIANÇA- CRIANÇA NA CONSTRUÇÃO DA AUTONOMIA}

O ser humano elabora formas de se relacionar com o mundo a seu redor, durante toda história da sua espécie, seja individual ou coletiva, busca conexão quando de seu convívio em sociedade. Portanto, o desenvolvimento não pode ser fundamentado apenas pelos fatores biológicos, mas também e nomeadamente pelas interações estabelecidas no decurso da vida do indivíduo.

Nesse ponto de vista, a criança desde o nascimento está em constante interação com o adulto que deve buscar frequentemente estimulá-la de forma a incorporá-la em sua cultura, que é repleta de significados acumulados historicamente. Primariamente a criança responde através de processos naturais derivados particularmente da herança biológica inerentes a todo ser humano e que por intermédio do adulto as "funções psicológicas complexas" (VYGOTSKY, 1989, p. 70-74) começam a tomar forma. No princípio, as crianças só assumirão forma na interação com o adulto, estes que nesta fase da vida da criança servem como agentes externos que intermediam o contato da criança com o mundo ao seu redor. Somente à medida que a criança cresce é que estes processos vão acontecendo dentro das próprias crianças e não mais através do adulto como transcorria inicialmente, assim chamados por Luria (2006, p. 27) de "processos interpsíquicos", ou seja, que acontecem dentro da criança através da internalização dos "meios historicamente determinados e culturalmente organizados". 
| Maria Fabrícia de Medeiros | Adelaide Alves Dias |

Além desses fatores apontados, o ambiente que vivemos é repleto de significados sociais que diferem em conformidade com a cultura que o sujeito está imerso, mesmo assim, cabe esclarecer que nenhuma pessoa concebe determinada experiência de forma igual, ainda que inseridas no mesmo contexto social e compartilhando características individuais parecidas, cada um se desenvolve singularmente. Sobre isso, Branco e Pinto (2009, p. 513) definem que: "o processo de desenvolvimento da criança envolve, portanto, uma contínua negociação de significados entre os atores em interação, onde as mensagens culturais são interpretadas e reinterpretadas de forma ativa pelos indivíduos”. Ou seja, a criança pequena desde que nasce demonstra potencialidades que se expandem a partir das interações sociais.

Ancoradas nos estudos de Vygotsky (1989) sobre o desenvolvimento da criança, que é uma temática ainda tão importante nos dias atuais, é que procuramos conceituar as interações, por se tratar da categoria primordial da nossa pesquisa. Acerca disso, Vygotsky (1989) já discutia e defendia o papel da interação como essencial na formação do desenvolvimento humano, uma vez que segundo o autor o desenvolvimento humano no início da vida é biológico e acontece através das interações sociais, ou seja, através das relações com o outro e com o mundo, sendo, portanto, nas relações sociais que nos desenvolvemos. Dito por Vygotsky (1989, p. 33) que:

Desde os primeiros dias do desenvolvimento da criança, suas atividades adquirem um significado próprio num sistema de comportamento social e, sendo dirigidas a objetivos definidos, são refratadas através do prisma do ambiente da criança. O caminho do objeto até a criança e desta até o objeto passa através de outra pessoa. Essa estrutura humana complexa é o produto de um processo de desenvolvimento profundamente enraizado nas ligações entre história individual e história social.

De acordo com a visão do teórico citado, nos primeiros meses de vida a atividade da criança é determinada pelo processo de maturação do organismo que acontece de forma individual, fortemente influenciada pelo uso que faz dos instrumentos e signos, e estes são os mediadores das interações das crianças com o mundo ao redor, portanto, é através do contato com o meio social cultural e histórico que a criança se desenvolverá, sendo que "[...] o início da inteligência prática na criança é independente da fala" (VIGOTSKY, 1989, p. 23).

Ao tratarmos de crianças pequenas é primordial conscientizar-nos em tornar estas interações cada dia mais saudáveis, baseadas no respeito e diálogo visando à construção da autonomia infantil. Ao tratar disso, Oliveira (1995, p. 38) diz: 


\begin{abstract}
A interação face a face entre indivíduos particulares desempenha um papel fundamental na construção do ser humano: é através da relação interpessoal concreta com os outros homens que o indivíduo vai chegar a interiorizar as formas culturalmente estabelecidas de funcionamento psicológico. Portanto, a interação social, seja diretamente com outros membros da cultura, seja através dos diversos elementos do ambiente culturalmente estruturado, fornece a matéria-prima para o desenvolvimento psicológico do indivíduo.
\end{abstract}

Dessa forma entendemos que as interações com indivíduos da mesma cultura ou de outras culturas é algo imprescindível tanto para a construção da autonomia, desenvolvimento de suas habilidades exploratórias e motoras, bem como para uma vida coletiva essencial a todo ser humano. A criança é um ser de natureza singular, que pensa e sente o mundo de um jeito próprio, nas interações que se estabelecem desde muito cedo, com a família inicialmente e posteriormente na creche, em que revelam empenho para compreender o mundo que as circundam, as relações contraditórias que presenciam e é através das brincadeiras que revelam "as condições de vida a que estão submetidas e seus anseios e desejos" (BRASIL, RCNEI, 1998, p. 21-22).

Desse modo, Vasconcelos et al. (2003) e Branco e Pinto (2009) discorrem sobre as interações, apontando que se fazem imprescindíveis, visto que o desenvolvimento humano é uma construção concebida com o outro, parceiro de interação, frequentemente um parceiro mais experiente que media o encontro da criança com o mundo em que paulatinamente se insere. Nenhuma pessoa vivencia as experiências de forma idêntica à outra, mesmo que inseridas em contexto sociocultural similar, ou que algumas características individuais sejam compartilhadas, sendo assim, constrói e reconstrói seu desenvolvimento através de tentativas de adaptação ao meio.

\title{
A AFETIVIDADE ATUANTE COMO UM FATOR IMPORTANTE PARA CONSTRUÇÃO DA AUTONOMIA
}

Entendemos autonomia como um processo que se compõe a partir das interações vivenciadas no cotidiano das crianças, e que o professor tem importante papel neste processo, podendo proporcionar espaço adequado alicerçado no diálogo e respeito para que as crianças sintam-se acolhidas e sintam-se à vontade para participar ativamente do cotidiano da creche, podendo fazer escolhas, opinar sobre as regras que devem ser estabelecidas em conjunto e não impostas horizontalmente. Sendo assim, deve-se considerar que paulatinamente vão "percebendo-se e percebendo os outros como diferentes, permitindo que possam acionar seus próprios recursos, o que representa uma condição essencial para o desenvolvimento da autonomia” (BRASIL, RCNEI, 1998, p. 14). 
| Maria Fabrícia de Medeiros | Adelaide Alves Dias |

Nessa direção, é a partir das interações com o mundo que se constroem possibilidades das crianças estruturarem bases para desenvolver sua autonomia e assim participar ativamente do meio social, refletindo, questionando e avaliando suas ações e consequências que estas lhe trarão. Dessa forma, ressaltamos o que aponta o documento RCNEI (1998) sobre autonomia:

[...] definida como a capacidade de se conduzir e tomar decisões por si próprio, levando em conta regras, valores, sua perspectiva pessoal, bem como a perspectiva do outro, é, nessa faixa etária, mais do que um objetivo a ser alcançado com as crianças, um princípio das ações educativas. Conceber uma educação em direção à autonomia significa considerar as crianças como seres com vontade própria, capazes e competentes para construir conhecimentos, e, dentro de suas possibilidades, interferir no meio em que vivem. Exercitando o autogoverno em questões situadas no plano das ações concretas, poderão gradualmente fazê-lo no plano das ideias e dos valores (BRASIL, RCNEI, 1998, v. 2, p. 14).

Nesta direção, elucidamos que autonomia perpassa pela capacidade de se autogerir e administrar decisões de modo a respeitar regras e valores levando em consideração seu querer e o querer do outro. Todavia, não há moralidade quando se entende apenas o próprio ponto de vista, incluindo os espaços da creche e da escola, em que é ofertada a Educação Infantil, visto que, são ambientes em que acontecem interações em uma amplitude considerável por ser heterogêneo, envolvendo histórias, culturas, crenças e vivências particulares bem diferentes.

De acordo com as Diretrizes Curriculares Nacionais para a Educação Infantil (DCNEI), as propostas pedagógicas devem respeitar alguns princípios dos quais destacamos: "Éticos, da autonomia, da responsabilidade, da solidariedade e do respeito ao bem comum, ao meio ambiente e às diferentes culturas, identidades e singularidades" (BRASIL, DCNEI, 2009, p. 16).

Neste contexto, torna-se imperativo que o professor envolva tais aspectos em sua prática cotidiana, visando tanto à promoção quanto o aprimoramento das interações afetivas entre professor-criança e criança-criança, bem como desenvolver as habilidades das crianças auxiliando-as a ascender ao patamar do autogoverno, quando conseguem fazer suas escolhas e controlar seus comportamentos e atitudes nos mais diversos ambientes.

Sobre a interação professor-criança, Tardeli (2003) revela que tanto o comportamento do professor quanto da criança é impulsionado à mudança e à adaptação por força da necessidade de convivência, que resulta na interação, possibilitando a expressão afetiva, intelectual e moral.

As interações que acontecem entre professores e crianças são muito mais que mero “contrato" profissional/pedagógico, na realidade se estabelece aí "uma relação direta, em 
| Maria Fabrícia de Medeiros | Adelaide Alves Dias |

que ambos compartilham histórias de sucessos e frustrações, de opressões e de incentivos" criando-se consequentemente "bases para o desenvolvimento das atitudes de dependência ou de autonomia" (TARDELI, 2003, p. 104).

Como podemos ver, as relações sociais são as responsáveis pela construção da autonomia, estas aconteçam no seio familiar, com os vizinhos, na creche e/ou em qualquer outro ambiente em que haja interações entre pessoas, Quando tratamos das crianças pequenas certamente intensifica-se o poder dessas relações exercido na vida delas, que se encontram em processo de desenvolvimento, construído prioritariamente através das interações. Nessa configuração, Dias (2005) pontua que:

O sujeito autônomo, enquanto protagonista de condutas morais, não se constitui de forma isolada, independentemente das condições sociais, históricas, políticas, econômicas e culturais. Ao contrário, define-se como aquele que, dialógica e dialeticamente, é capaz de articular, de forma crítica e ativa, vontade subjetiva (individual e pessoal) e vontade objetiva (instituições sociais e cultura), questionando, refletindo, respondendo, influenciando e sendo influenciado pelas ocorrências do seu ambiente, construindo e reconstruindo dinamicamente as experiências que vive tanto no plano individual quanto coletivamente (DIAS, 2005, p. 371).

Nessa conjuntura, o professor deve estar atento e consciente de que o ambiente criado através de sua postura pessoal e profissional, sendo estas indissociáveis, influencia positivamente ou negativamente as interações entre professor-criança e criança-criança, culminando ou não na construção da autonomia, visto que ninguém se constitui sujeito autônomo estando à parte do mundo, mas sim em contato direto com este, influenciando e sendo influenciado, criando e recriando a partir das situações vividas.

Quando tratamos da criança pequena em um contexto afetivo intensifica-se o grau de cuidado e responsabilidade ao lidar e conduzir as relações interpessoais e os sentimentos envolvidos, pois estes estão envoltos em um mundo de constantes descobertas que podem positivamente ou negativamente interferir no desenvolvimento e formação de seu eu, bem como na construção da autonomia.

\section{MÉTODO}

\section{Sujeitos}

Os sujeitos dessa pesquisa foram a professora, a monitora e as crianças de 3 (três) anos da turma do Maternal 2 de um Centro de Referência em Educação Infantil (CREI) da cidade de João Pessoa - PB. 
A professora titular da turma pesquisada tem 24 (vinte e quatro) anos, Licenciatura em Pedagogia, atua no magistério há 7 (sete) anos e trabalha a 1 (ano) e 5 (cinco) meses no CREI. A monitora tem 56 (cinquenta de seis) anos, formação incompleta em Pedagogia, atuante no magistério há 20 (vinte) anos e 5 (cinco) meses e no CREI há 1 (ano) e 5 (cinco) meses, ambas são Prestadoras de Serviço (PS) contratadas pela Secretaria Municipal de Educação, cumprem carga horária diária de 8 (oito) horas em tempo integral, totalizando 40 (quarenta) horas semanais.

A turma do Maternal 2 tinha matriculadas 26 (vinte e seis) crianças, sendo 16 (dezesseis) meninos e 10 (dez) meninas, todos com idade de 3 (três) anos, variando apenas os meses, mas nenhum deles tinha 4 (anos) completos até a finalização das observações, 2 (duas) crianças aparentemente possuíam algum tipo de necessidade especial mas ainda sem diagnóstico.

\section{Instrumentos e Procedimentos para coleta de dados}

Os instrumentos utilizados na pesquisa foram o questionário para traçar o perfil dos sujeitos adultos (professora e monitora) e o diário de campo, para registrar os dados da observação. Também foi utilizada câmera de vídeo para filmagem da rotina da turma no CREI.

A observação participante foi realizada em 8 (oito) meses e aconteciam sem dia ou horário marcados. As videogravações foram feitas em diversos momentos (brincadeiras livres e/ou dirigidas, atividades pedagógicas, hora da alimentação e banho, acolhida pela manhã e despedida à tardinha) e episódios aleatórios do cotidiano das crianças nos quais identificamos alguma manifestação quanto aos pontos investigados. De todo material videogravado, selecionamos 3 (três) episódios, totalizando aproximadamente 2 (dois) minutos e 58 (cinquenta e oito) segundos e 429 MB (megabytes).

Todos os procedimentos éticos foram devidamente observados. A pesquisa foi submetida ao Comitê de Ética na Pesquisa com seres humanos (Protocolo n ${ }^{\circ}$ 0655/14, CAAE: 393964.14.0000.5188) e obteve aprovação.

\section{Procedimentos para análise dos dados}

A definição de recursos e procedimentos que abarcassem a complexidade do tema em questão fez-se primordial, em vista disso, a utilização de câmera para videogravar as observações sem hesitação foi o que se mostrou mais adequada, visto que nos permitiu 
| Construção da autonomia na Educação Infantil: interações entre crianças e professoras |

| Maria Fabrícia de Medeiros | Adelaide Alves Dias |

captar elementos verbais e não verbais, entonação, gestos, expressões faciais, acontecimentos fugazes e que provavelmente não se repetiriam, entre outros elementos sutis que vão além da fala e apenas o olhar do pesquisador certamente não apreenderia.

Diante de um vasto material videogravado foi necessário definir qual olhar inicial seria dado aos vídeos, com o objetivo de facilitar as análises, portanto, como já mencionado, dividimo-los em 3 (três) tipos de eixos condutores das análises: criançacriança, professora ou monitora-criança e criança-professora ou monitora, buscando visualizar possíveis interações iniciadas tanto pela professora ou pela monitora quanto pela criança direcionadas entre si, o que para nós significava consequentemente que as interações existiam de algum modo no ambiente pesquisado.

\section{RESULTADOS E DISCUSSÃO}

Para efeito deste artigo, apresentaremos os resultados de três dos episódios interativos analisados, um referente a cada uma das categorias elencadas em nossa pesquisa, que são: interações criança-criança, interações professora ou monitora-criança e interações criança-professora ou monitora, respectivamente. Os nomes dos sujeitos foram preservados, utilizamos, portanto, nomes fictícios.

\section{Interação criança-criança}

Nesta categoria de análise temos uma interação entre crianças.

Quadro 01 - Episódio: Fazendo uma cobra bem grande

\begin{tabular}{|c|c|c|c|c|c|}
\hline $\mathbf{N}^{\mathbf{o}}$ & Episódio & Duração & $\begin{array}{l}\text { Local da } \\
\text { Filmagem }\end{array}$ & Participantes & Síntese do Episódio \\
\hline 01 & $\begin{array}{l}\text { Fazendo } \\
\text { uma cobra } \\
\text { bem } \\
\text { grande. }\end{array}$ & $1 \mathrm{~min} .19 \mathrm{~s}$. & Sala. & $\begin{array}{l}\text { Alisson, Ciro, } \\
\text { Carlos } \\
\text { Vítor. }\end{array}$ & $\begin{array}{l}\text { A interação aconteceu em torno } \\
\text { de um brinquedo (cobra grande } \\
\text { feita de massa de modelar) } \\
\text { construído por Alisson, que } \\
\text { chamou atenção e desejo dos } \\
\text { colegas de ter uma igual. }\end{array}$ \\
\hline
\end{tabular}

Transcrição: as crianças estão na sala brincando com massa de modelar, Alisson fez uma "cobra bem grande", chamando bastante atenção dos colegas, Ciro se aproximou com seu 
pedaço de massa de modelar e pediu que Alisson fizesse uma igual para ele, este aceitou o pedido e começou enrolar a massa com força sobre a mesinha. Ciro pegou nas duas pontas da "cobra" já pronta do colega e pareceu analisar o tamanho e disse: "minha peba (este foi o nome utilizado pela criança que pareceu-nos denominar a cobra pelo contexto da fala) é gande (grande)" dando batidinhas com os dedos na "cobra" do colega, deu uma olhadinha para a pesquisadora e se voltou para o colega que, fazendo força, enrolava a massa e dizia: "se você destuir (destruir) eu não faço mais não". Ciro encostado na mesinha em silêncio contemplava o colega fazendo seu brinquedo. Alisson continuava concentrado, mas levantou o olhar rapidamente para Ciro e falou: "não destua (destrua) viu”. Ciro, então, afastou um pouco da mesinha e disse: "bem gande (grande) assim ó", mostrando o tamanho com as mãos, deixando os braços totalmente esticados, Alisson sem levantar o olhar respondeu: "tá". Carlos se aproximou da mesa em que estavam Alisson e Ciro e perguntou "que isso?", apontando para a "cobra grande" de Alisson que já estava pronta, mas não obteve resposta de nenhum dos dois colegas que já interagiam e, portanto, ficou na mesa ao lado, dependurado, balançando as pernas. Outra criança (Vítor) se aproximou de Ciro e ficou ao seu lado de pé observando Alisson enrolar a massa de modelar. Vítor tenta pegar na mão de Ciro dizendo "vá sentar" e olhou para a monitora como se esperasse essa confirmar sua fala, já que ela havia alertado outro colega há poucos segundos, dizendo: "devagar, viu, Carlos, senão vai sentar", mas Ciro puxou a mão tentando se soltar. Vítor falou novamente "vá sentar" e tentou pegar a mão do colega outra vez, mas Ciro deu dois tapinhas no ar e continuou a olhar como se nada tivesse acontecido. Vítor só desistiu e se afastou quando a monitora perguntou: "Vítor, o que tá havendo?". Ciro colocou uma mão em cima da outra e fez um gesto com as mãos como se estivesse enrolando e ensinando Alisson como fazer, já que este usava as mãos separadas para enrolar a massa e não uma em cima da outra como mostrava Ciro, dizendo: "assim ó”, chamando atenção de Alisson para que visse, demonstrando inquietude que podia ser pelo desejo dele mesmo fazer "a cobra", ou para que o colega acabasse logo de fazê-la. A "cobra" partiu em duas e Ciro repetiu novamente o gesto com as mãos ensinando como o colega devia fazer a "cobra" e falou: "assim ó, assim ó", Alisson continuava concentrado e levantou apenas o olhar sem movimentar a cabeça, Ciro colocava a mão em cima de um dos lados da cobra visivelmente na tentativa de ajudar Alisson, já que parecia que, quando ele enrolava uma extremidade, a outra balançava, podendo partir-se novamente. Alisson retirou a mão do colega, dizendo "sai", e Ciro repetiu o gesto com as mãos levando cada uma às extremidades do corpo e

\footnotetext{
${ }^{1}$ Nas transcrições dos vídeos nas falas das crianças indicadas por aspas colocamos a tradução de algumas
} palavras entre parênteses com o intuito de facilitar o entendimento do leitor. 
| Maria Fabrícia de Medeiros | Adelaide Alves Dias |

disse: "bem grande assim ó", enquanto enrolava a massa freneticamente. Alisson levantou a cabeça rapidamente e disse "é". Carlos que estava sempre ali por perto observando e que anteriormente já havia feito pergunta ao colega sobre o brinquedo em voga, aproximou-se novamente, encostou-se na mesinha ao lado, olhou um instante e pegou por uma das pontas a "cobra" que estava sendo feita por Alisson e saiu correndo pela sala. Alisson deu uns pulinhos gritando "é de Ciro, é de Ciro", mas permaneceu em seu lugar à espera do desfecho da cena. Parece não ter ido à busca da "cobra" que fazia para o colega porque precisava tomar conta da sua "cobra" que permanecia intacta na mesinha, ao contrário de Ciro que correu atrás de Carlos, mas parou no caminho e chamou a monitora acenando com a mão.

Discussão do episódio: O episódio interativo aconteceu na maior parte do tempo em uma díade apesar de se inserirem outras duas crianças. O recorte do vídeo deu-se no momento que a monitora foi inserida no episódio por Ciro, que acena pedindo ajuda para pegar a "cobra" de massa que Carlos pegou. Portanto, a fim de analisarmos apenas as interações entre criança-criança, categoria em que o vídeo foi posto, foi que optamos pelo recorte neste ponto, bem como por se tratar de um episódio extenso.

O episódio continuou, e, apesar da interação se estabelecer na maior parte do tempo baseada em díade e tríade, passou a se configurar em uma interação em grupo (outras crianças se aproximam com suas massas de modelar e ficaram juntas na mesinha conversando e brincando), tornando o vídeo bastante extenso para análise, nos remetendo ao que revelam Pedrosa e Carvalho (2005, p. 432), quando expõem a decisão de recorte interno de episódios, feita na pesquisa, em que “[...] o contínuo do registro recortado em episódios revelou-se ainda grande demais para análise. Decidiu-se, então, realizar recorte interno ao episódio". Assim, os primeiros recortes foram feitos com base no que já discutimos antes, mas neste caso foi necessário fazer recortes internos pelos motivos citados, explicitando mais uma vez a complexidade da análise, o que demandou nossa atenção e escolhas.

O episódio iniciou-se quando Alisson fez uma "cobra" grande com a massa de modelar que havia sido entregue pela monitora para todas as crianças brincarem livremente, no contexto observado entendemos por atividades "livres" os momentos que a professora não estava ensinando algo que faz parte do planejado, muito embora, ainda assim, as crianças nem sempre podiam escolher como e com o que brincar.

A massa de modelar que foi entregue às crianças tornou-se um objeto significante com o qual a criança usou a imaginação e criou um brinquedo, mas não um brinquedo 
| Maria Fabrícia de Medeiros | Adelaide Alves Dias |

aleatório, e sim baseado na aula que foi dada naquela mesma semana em que se debateu sobre animais e entre eles estava a cobra: "réptil de vários tamanhos, porém geralmente o tamanho grande prevaleceu, com referências a picadas e em algumas espécies, o veneno foi destacado, que por ser tão forte, pode até matar um ser humano" (professora Ana, registro feito no diário de campo).

O brinquedo construído por Alisson chamou atenção dos colegas, especialmente de Ciro que pareceu enxergar em Alisson o único capaz de fazer outra "cobra" pra ele da mesma forma que fizera a primeira que é tomada como parâmetro de algo grande e legal. Deixando, portanto, expresso em sua fala, ações e expressões corporais que nos pareceu ser de admiração e sentimento de capacidade superior que atribui ao colega Alisson, ao dizer: "bem gande assim ó... igual a sua".

Evocamos Vygotsky (1989, p. 109) ao explicar que: “[...] é enorme a influência do brinquedo no desenvolvimento de uma criança". Isso ficou explicitado durante todo o episódio, em que as crianças demonstraram o quanto estavam concentradas e levavam a sério seu propósito de construir o brinquedo. Elas debatiam, elaboravam regras entre elas, conforme confirmamos na fala de Alisson: "se você destuir, eu não faço mais não". Nisso, Ciro entendeu a condição e demonstrou comportamento de aceitação, repetindo sua fala anterior: "bem gande, assim ó", confirmando, portanto, que mesmo diante da regra criada pelo colega queria sua cobra grande pronta.

Em alguns momentos Ciro tentava ensinar o colega como se fazia a cobra, coloca uma mão sobre a outra fazendo o gesto de enrolar, demonstrando até certa ansiedade, mas não interrompia Alisson e o deixava fazer o brinquedo até o fim, controlava seu impulso de pegar de volta sua massa de modelar para que ele próprio pudesse fazer seu brinquedo. Atestamos, portanto, aparente respeito consciente ou inconscientemente que Ciro atribui à regra inicial estabelecida por Alisson e talvez a capacidade superior que pareceu atribuir ao colega e que lhe traria o benefício final de ter a sua tão desejada "cobra". Sobre isso, nos remetemos a afirmativa de Vygotsky (1989) que explica:

continuamente a situação de brinquedo exige que a criança aja contra o impulso imediato [...] o maior autocontrole da criança ocorre na situação de brinquedo [...] comumente, uma criança experiencia subordinação a regras ao renunciar a algo que quer, mas, aqui, a subordinação a uma regra e a renúncia de agir sob impulsos imediatos são os meios de atingir o prazer máximo (VYGOTSKY, 1989, p. 113).

Neste contexto, Ciro optou por aguardar o colega fazer o brinquedo, demostrando fisicamente estar controlando seus impulsos, enquanto Alisson se empenhava para validar toda sua habilidade certamente acentuada pelo próprio Ciro. As crianças estavam tão 
envoltas e atentas no momento que não recebiam ou logo afastavam as interferências externas, a exemplo dos colegas Vítor que tentava intervir puxando Ciro para sentar e Carlos que tentava se envolver na brincadeira, se aproximando e perguntando algumas vezes "o que é isso", referindo-se ao brinquedo que estava sendo feito.

Carlos só foi levado em consideração e teve atenção das crianças que interagiam quando pegou a cobra e saiu correndo com ela pela sala, demonstrando claramente que queria uma cobra também ou mesmo para apenas brincar um pouco com a do colega, mas pela dificuldade que apresentava quase sempre em comunicar-se com as pessoas de modo geral, não soube expressar seu desejo falando e resolveu simplesmente pegar para si o brinquedo. Muito embora Ciro não tenha um perfil de criança que espera por ninguém para resolver as situações, na maioria das vezes revidando, nesta ocasião, em especial, pediu ajuda da monitora para resolver a ocorrência e pegar sua cobra de volta.

Nesse momento, verificamos, portanto, o cuidado e afetividade que tanto Ciro quanto as demais crianças têm quando se trata de Carlos, inclusive é recorrente a afirmação vinda das próprias crianças de que estão ajudando a cuidar de Carlos, esse fato se deve aparentemente às dificuldades de comunicação apresentadas pela criança. Diante do que foi dito, cabe ressaltar que notamos os esforços da professora e da monitora para inserir Carlos nas atividades diárias, fossem individuais ou coletivas, muito embora ele se mostrasse quase sempre disperso do grupo, bastante inquieto e se dispusesse poucas vezes a participar de determinadas atividades, principalmente as que demandavam estar inserido no grupo, pois parecia impaciente, aparentemente gostava de brincar sozinho, mas também interagia a seu modo com as demais crianças, professora e monitora. Quando contrariado por algum adulto ou pelos colegas, se irritava e chegava a bater e a gritar, parecia não saber lidar e externar muito bem ainda com seus sentimentos e desejos. Talvez por este motivo as interações com as outras crianças se desvelassem mais dificultosas, diferentemente das interações com a professora e a monitora que através da convivência passaram a compreender melhor o comportamento, desejos e sentimentos de Carlos.

Ele gostava bastante das atividades de pintura e nestes momentos sentava-se em qualquer cadeirinha sem que ninguém precisasse pedir, inclusive dando vontade de sentar na cadeira que já havia algum colega sentado, chegava, empurrava o colega e sentava em seu lugar, fato este que acontecia com qualquer coisa que Carlos desejasse, continuamente. Tais cenas resultavam em choro da outra criança e gritos de Carlos ao ser retirado pela professora ou pela monitora, posteriormente havia todo o processo de conversa e pretensão de ensinar a Carlos porque não podia agir daquela maneira, mesmo ele mostrando entender pelo menos de acordo com suas condições, voltava a repetir em outras 
| Maria Fabrícia de Medeiros | Adelaide Alves Dias |

oportunidades, muito embora tenhamos percebido uma diminuição considerável de tais atos durante o período da pesquisa e evolução de Carlos no modo de interagir com seus pares.

Após tudo resolvido e calmo, ao menos naquele determinado episódio, Carlos ficava aguardando a atividade sempre com sorriso no rosto, fazia sua atividade, e quando decidia que havia acabado, entregava a professora ou a monitora e voltava a brincar pela sala e mexer com um e outro colega, visto que ele não parava quieto, mas as crianças incentivadas pela professora e pela monitora apresentavam paciência com Carlos. A esse respeito, o RCNEI (1998) assegura que:

\footnotetext{
A criança que conviver com a diversidade nas instituições educativas, poderá aprender muito com ela. Pelo lado das crianças que apresentam necessidades especiais, o convívio com as outras crianças se torna benéfico na medida em que representa uma inserção de fato no universo social e favorece $o$ desenvolvimento e a aprendizagem, permitindo a formação de vínculos estimuladores, o confronto com a diferença e o trabalho com a própria dificuldade (BRASIL, RCNEI, 1998, v. 1, p. 35).
}

Nesse entendimento, são comprovadamente favoráveis ao desenvolvimento das crianças as interações dentro desse ambiente diverso que constitui as instituições infantis. As crianças compartilham e assimilam novos saberes provenientes das culturas e histórias de vida de cada um, tão importantes nestas relações. O convívio das crianças com Carlos é importante e proveitoso para ambas as partes que aprendem desde cedo o respeito às diferenças e proporciona a Carlos um recinto repleto de estímulos oriundos das outras crianças.

A brincadeira é importante na vida das crianças e favorece o desenvolvimento, tendo como base os distintos momentos de interações, e nesses, percebemos durante as observações que as crianças brincam quase todo tempo, seja com outra criança, em pequenos grupos ou sozinha em seu mundo de faz de conta, e até mesmo quando a professora ou a monitora requisitavam silêncio e organização às crianças, estas transgrediam as ordens e davam sempre um jeito de brincar.

Destarte, percebemos a influência do brinquedo nas interações, neste caso acontece o que Wallon (2007, p. 55) denomina de "brincadeiras de fabricação", estas, levam a criança a se divertir através da junção e combinação de objetos, havendo modificação, transformação e criação de novos objetos. Muito embora no contexto da sala em questão, não tenha espaço privilegiado com brinquedos diversificados, aliás, quase não possui brinquedos e a organização não é adequada, pois a sala apesar de ter um tamanho razoável é cheia de mesas, cadeiras e outros objetos que ocupam bastante espaço. Ainda assim, as 
| Construção da autonomia na Educação Infantil: interações entre crianças e professoras |

| Maria Fabrícia de Medeiros | Adelaide Alves Dias |

crianças ultrapassam esses limites e conseguem fortalecer as interações através de brinquedos construídos e brincadeiras inventadas por elas mesmas, evidenciando a autonomia que possuem e as que estão sendo construídas a partir das interações realizadas.

\section{Interação professora ou monitora-criança}

Nesta categoria de análise temos uma interação que foi iniciada pela professora voltada para as crianças.

Quadrp 02 - Episódio: A professora é um mágico

\begin{tabular}{|c|l|l|l|l|l|}
\hline $\mathbf{N}^{\mathbf{0}}$ & Episódio & Duração & $\begin{array}{l}\text { Local da } \\
\text { Filmagem }\end{array}$ & Participantes & Síntese do Episódio \\
\hline 05 & $\begin{array}{l}\text { A professora } \\
\text { é um mágico. }\end{array}$ & $\begin{array}{l}1 \mathrm{~m} \text { min. } \\
23 \mathrm{~s} .\end{array}$ & Sala. & $\begin{array}{l}\text { Professora e } \\
\text { todo grupo } \\
\text { de crianças. }\end{array}$ & $\begin{array}{l}\text { A interação aconteceu durante } \\
\text { aula, a professora } \\
\text { apresentava o tema e fez } \\
\text { questionamentos e as crianças } \\
\text { participaram ativamente. }\end{array}$ \\
\hline
\end{tabular}

Fonte: elaboração das autoras (2017).

Transcrição: nesse dia, a professora Ana deu sua aula vestida de mágico, paramentada com capa preta e cartola, ela estava de pé e as crianças todas sentadas em suas cadeiras. As mesas estavam em formato de U. A professora chamava a cartola de chapéu e dizia que o chapéu daria uma surpresa para a turma e tentava tirá-la de dentro do chapéu, o colocava entre as pernas, curvava o tronco e fingia tentar puxar a surpresa já que o chapéu, segundo ela, não queria soltar. As crianças tiveram diversas reações: umas estavam ajoelhadas nas cadeiras e debruçadas nas mesas, outras permaneceram sentadas em suas cadeiras, algumas dão risadas, outras parecem estáticas. A professora voltou à posição ereta e disse: "não soltou", se referindo ao chapéu não ter soltado a surpresa. Então, ela colocou a mão novamente dentro do chapéu, mas não tirava nada e dizia: "pera (espera) ấ", levando o chapéu até o ouvido, depois o levava até a boca como se fosse conversar com o chapéu: “por que você não quer soltar?", segurou o chapéu ao lado do corpo, levantou uma das mãos e deu um suposto recado do chapéu: "ele disse que vocês vão saber o que é”, mais uma vez levou o chapéu até a boca e perguntou: “o que?”, abaixou o chapéu na altura do próprio umbigo e com a mão dentro do chapéu falou: "hiii, entregou". Durante todo o tempo as crianças permaneceram basicamente nas mesmas reações citadas anteriormente, também ficaram atentas e demonstraram curiosidade em descobrir o que seria a surpresa. A 
professora puxou rapidamente de dentro do chapéu a letra A, mas escondeu outra vez, deu uma olhadinha sorrindo e falou: "já me entregou, eu tô vendo o que é”, encostou o chapéu na barriga ainda com a letra escondida e sorrindo questionou a turma: "quem adivinha o que é?", prontamente Vitória respondeu: “uma letra”, neste momento surgiu um breve silêncio na sala, como se aguardassem a confirmação da professora, mas o silêncio foi rompido pelas risadas das crianças e a professora mostrou uma parte da letra e perguntou: “que letra é essa?". Vitória mais uma vez se adianta e respondeu: "letra E”, a professora rebateu com outro questionamento: “é a letra E? Será?" e começa puxando a letra de dentro do chapéu bem devagar e mostrando-a, agora algumas crianças começaram a dá seus palpites: "letra E”, “é o O”, "letra E”. Vitória continuou: "você tem que dizer abra cadabra", a professora aceitou a sugestão e repetiu: "abra cadabra" e deu um sopro na letra que já quase aparecia por completo e quando a letra finalmente surgiu ela perguntou: "que letrinha é essa?", ouvimos mais claramente a voz mais grave de Vitória: "a letrinha A", mas várias outras crianças também responderam.

Discussão do episódio: $O$ episódio interativo exposto aconteceu na aula, entre a professora Ana e o grupo de crianças que compareceu ao CREI naquele dia. O momento da atividade pedagógica evidenciada no episódio faz parte da rotina diária existente no CREI, que é organizada pelos profissionais em reunião. Foi durante a atividade que se desencadeou a interação conjunta entre professora-crianças, esta aconteceu no início do ano em curso. A rotina já faz parte do cotidiano da Educação Infantil oferecida no CREI, que corresponde à organização do tempo-espaço. Sobre essa temática, Macêdo (2014, p. 111) aponta que, “[...] a rotina, o ritual, o fazer sempre o mesmo traz em si o novo, o inusitado. Como sujeitos sociais, fazemos parte de um cotidiano desde que nascemos", portanto, notadamente as crianças observadas, em sua maioria, já se mostravam adaptadas à rotina estabelecida pelos adultos.

$\mathrm{Na}$ cena, a professora interpretou um mágico e iniciou a interação fazendo perguntas às crianças e estas respondiam. Nessa ocasião, houve uma troca importante de saberes, a professora demonstrava receptividade ao ouvir e respeitar as colocações das crianças, bem como criativamente utilizava-se do mundo imaginário e da curiosidade infantil para dar sua aula de forma interativa e totalmente inserida no mundo das crianças, de forma a fortalecer vínculos e propiciar a construção do conhecimento e da autonomia das crianças.

As crianças validaram nossa percepção através de seus comportamentos e falas, quando se envolveram e se comunicaram com a professora na tentativa de adivinhar qual 
| Maria Fabrícia de Medeiros | Adelaide Alves Dias |

presente o chapéu iria dar a turma, bem como nas expressões faciais (sorrisos, espanto) e corporais (ajoelhadas nas cadeiras e debruçadas sobre a mesa), indicando envolvimento com a aula. Muito embora tenhamos constatado poucas emoções e entusiasmo demonstrados pelas crianças, o que é típico da idade, principalmente em situações que mexem com a imaginação, este fato talvez aconteça pela organização da sala que dificulta a livre circulação das crianças, mas sobretudo pela regulação da professora e da monitora por ordem e silêncio das crianças.

Mesmo assim, enxergamos as crianças reagindo claramente àquela organização enfileirada em que todas permaneciam sentadas nas mesinhas que estavam dispostas em formato de $\mathrm{U}$, denotando as marcas persistentes da pedagogia tradicional. De acordo com Dias (1999, p. 13), "a escola tradicional estimula a moral heterônoma nos seus alunos a partir de determinadas ações educativas baseadas na coação”, práticas estas evidenciadas na pressão do professor sobre o aluno por meio de regras impostas e fortalecimento do individualismo que diverge da cooperação entre os indivíduos. De forma complementar a esse entendimento, o RCNEI nos fala sobre a organização do espaço e seleção dos materiais:

\footnotetext{
A organização dos espaços e dos materiais se constitui em um instrumento fundamental para a prática educativa com crianças pequenas. Isso implica que, para cada trabalho realizado com as crianças, deve-se planejar a forma mais adequada de organizar o mobiliário dentro da sala, assim como introduzir materiais específicos para a montagem de ambientes novos, ligados aos projetos em curso (BRASIL, RCNEI, 1998, v. 1, p. 58).
}

Também, precisamos reconhecer que a organização do espaço da sala é igualmente importante ao ato de planejar, ambos se completam e quando bem concebidos resultam em práticas pedagógicas mais eficazes, com vistas ao alcance de objetivos específicos e previamente definidos, pretendendo o desenvolvimento global das crianças. Logo, proporcionar um ambiente adequado de modo que possam movimentar-se livremente se faz primordial.

Notamos que as crianças exibiam tranquilidade ao falar e expressar ideias, consequentemente, participavam ativamente da aula, o que denotava que havia um espaço favorável para as suas expressões, talvez, caso contrário, possivelmente encontraríamos crianças retraídas com receio de falar e agir diante das diversas situações do dia a dia. Muito desse ambiente interativo e propício à aprendizagem das crianças, provavelmente acontecesse porque as crianças se reportavam a professora e a monitora em momentos diversos da rotina sem que fossem ignorados ou censurados, alicerçando relações de confiança, empatia e respeito mútuos. 
Pedrosa (1996, p. 50-51) afirma que:

\begin{abstract}
A empatia não é um comportamento observável, mas um estado complexo inferido, cujas propriedades podem ser determinadas, apenas, através de evidências indiretas tais como a orientação de um comportamento para um objetivo, as suas consequências, a consistência de certas relações estabelecidas em um certo intervalo de tempo e a natureza das reações de parceiros para os comportamentos.
\end{abstract}

A empatia nas situações interativas é muito comum, e é apresentada principalmente quando o sujeito coloca-se no lugar do outro ou mesmo como resposta de uma pessoa ao estado afetivo da outra. Conseguimos, portanto, visualizar no episódio que a professora criou um ambiente afetivo, proporcionando às crianças o estabelecimento de vínculos positivos demonstrados nos comportamentos, que comprovadamente existia reciprocidade.

Uma das crianças, Vitória, atestou possuir conhecimento prévio do que deveria ser dito por um mágico com sua varinha ao tentar tirar algo de seu chapéu e fala para a professora: "você tem que dizer abracadabra". A professora repete o que a aluna ensinou, evidenciando a importância que atribuiu ao ensinamento da criança, estimulando novas iniciativas tanto de Vitória quanto das demais crianças, as quais presenciavam o comportamento de aceitação e respeito que a professora demonstrara naquele momento.

Optamos por recortar o episódio neste ponto porque a professora deu uma pausa para organizar a sala para o próximo momento, que seria sobre o tema que foi debatido, que culminava em uma atividade de pintura na "folhinha", atividade muito comum ainda nas salas de Educação Infantil que consiste em uma prática pedagógica escolarizada que exige sistematização e certa rigidez. Portanto, a prática pedagógica da professora, seguida pela prática da monitora quando assumia a sala na ausência da professora, oscilavam consideravelmente entre uma prática dinâmica, criativa, que estimulava a participação, mesclando-se com uma prática tradicionalista que coibia de certo modo o desenvolvimento e a evolução das crianças, que parecia colocar à prova a capacidade e competência destas.

\title{
Interação criança-professora ou monitora
}

Nesta terceira categoria de análise temos uma interação iniciada pela criança direcionada à monitora. 
Quadro 03 - Episódio: Parabéns, você conseguiu!

\begin{tabular}{|c|c|c|c|c|c|}
\hline $\mathbf{N}^{\mathbf{o}}$ & Episódio & Duração & $\begin{array}{l}\text { Local da } \\
\text { Filmagem }\end{array}$ & Participantes & Síntese do Episódio \\
\hline 10 & $\begin{array}{l}\text { Parabéns, } \\
\text { você } \\
\text { conseguiu! }\end{array}$ & $16 \mathrm{~s}$. & Sala. & $\begin{array}{l}\text { Monitora e } \\
\text { Ciro. }\end{array}$ & $\begin{array}{l}\text { A criança chamou a monitora } \\
\text { para ver o que ele fez com a } \\
\text { massa de modelar, ela atendeu } \\
\text { ao chamado parabenizando-o e } \\
\text { incentivando-o. }\end{array}$ \\
\hline
\end{tabular}

Fonte: elaboração das autoras (2017).

Transcrição: a monitora estava ajoelhada no chão ao lado de uma criança, olhando e conversando com ela, que fazia seu animalzinho de massinha de modelar, tema da aula "animais domésticos e animais selvagens". De repente, Ciro saiu de sua cadeira e se dirigiu até a monitora para chamá-la, pegou em sua mão e falou: “já acabei tudo meu animal”2; a monitora respondeu: "vou olhar" já levantando-se, a criança foi na frente parecendo satisfeita pela aceitação da monitora ao seu convite, passou pelas cadeiras colocando a mão em quase todas elas, ainda deu uma olhadinha para o colega, mas continuava andando. Outra criança chamou a monitora, ela olhou, mas foi atender ao chamado de Ciro primeiro. Ciro chegou na sua mesinha e em pé, sorrindo e olhando para a monitora, apontou para o seu "animal" feito de massinha e falou: "aqui ó" e se segurou na cadeira, parecia esperar o que a monitora iria dizer. A monitora bateu palminhas e disse: "eita! Parabéns, você conseguiu!’. Ciro balançou a cabeça positivamente, ela então se agachou mais próximo da criança e falou: "tentou e conseguiu" e Ciro deu uma olhadinha para a monitora apenas virando o olhar sem mover a cabeça e esboçou uma fisionomia de satisfação pelo dever cumprido.

Discussão do episódio: A monitora mais uma vez como já acontecido em tantos outros episódios, estava ajoelhada ao lado da cadeira de uma criança conversando, quando Ciro chegou e requisitou sua presença para olhar o que ele havia feito com a massa de modelar. Prontamente a monitora atendeu o chamado, levantou e foi até a mesinha de Ciro, ela sempre mostrou disponibilidade às demandas das crianças, o que se reflete na constante

\footnotetext{
2 Neste momento, a câmera balança um pouco e sai de foco porque outra criança se aproxima por trás da pesquisadora abraçando-a fortemente, fazendo-a balançar, o que não comprometeu o entendimento do episódio por ter sido muito rápido o desfoque, normalizando logo em seguida a filmagem.
} 
| Construção da autonomia na Educação Infantil: interações entre crianças e professoras |

| Maria Fabrícia de Medeiros | Adelaide Alves Dias |

solicitação das crianças por sua presença. Esse entendimento é observado nos encaminhamentos de Wallon (2007, p. 69) sobre a atenção que a criança exige ao realizar algum tipo de atividade, ao dizer que: “[...] a criança pequena quer ser vista quando as pratica e não cessa de solicitar a atenção dos pais, dos mais velhos".

Acerca disso, notamos nas crianças a frequente necessidade de quererem ser vistas nas mais diversas atividades, e constatamos que a professora e a monitora se mostram continuamente dispostas a atender às reivindicações e necessidades das crianças. Provavelmente, este é um fator que ocasiona tamanha tranquilidade e continuidade de solicitações por atenção requeridas pelas crianças. Caso contrário, se existissem recusas por parte da professora ou da monitora aos chamados das crianças, possivelmente as crianças não fossem tão espontaneamente solicitar "os olhares" da professora e da monitora, que, de qualquer forma, estão propiciando que as crianças tenham autonomia nas tomadas de decisões, que neste caso exemplificado são tomadas de decisões com assertivas positivas.

Com efeito, dialogamos com o que aponta o RCNEI sobre a importância do professor quanto interventor na instituição de Educação Infantil:

\begin{abstract}
A intervenção do professor é necessária para que, na instituição de Educação Infantil, as crianças possam, em situações de interação social ou sozinhas, ampliar suas capacidades de apropriação dos conceitos, dos códigos sociais e das diferentes linguagens, por meio da expressão e comunicação de sentimentos e ideias, da experimentação, da reflexão, da elaboração de perguntas e respostas, da construção de objetos e brinquedos etc. Para isso, o professor deve conhecer e considerar as singularidades das crianças de diferentes idades, assim como a diversidade de hábitos, costumes, valores, crenças, etnias etc. das crianças com as quais trabalha respeitando suas diferenças e ampliando suas pautas de socialização (BRASIL, RCNEI, 1998, v. 1, p. 30).
\end{abstract}

Portanto, a monitora transmitiu confiança e estímulo a Ciro, primeiro por não ignorar seu pedido e segundo pela reação dela ao ver o que Ciro havia elaborado com a massa de modelar, demonstrando sinceridade, que foi percebida pela criança que, visivelmente, pareceu sentir orgulho de si mesma. A massa de modelar foi um instrumento que permitiu a criança desenvolver a imaginação e criatividade, muito embora ainda tenhamos percebido que apenas ela limitava as brincadeiras e consequentemente as interações; não conseguimos presenciar criações altamente ricas superando a simplificação que o instrumento faculta a qualquer momento interativo.

Nesse sentido, a professora e a monitora procuravam promover interações baseadas na afetividade, respeito e atenção às crianças, bem como uma prática criativa e estimuladora, à medida das condições físicas e materiais permitidas pela instituição e do próprio conhecimento experiencial e teórico apreendido por ambas. Mesmo que as dificuldades e falhas existissem, mas o esforço e dedicação da professora e da monitora 
eram perceptíveis, assim como a construção da autonomia pelas crianças mesmo diante das adversidades.

\section{CONSIDERAÇÕES FINAIS}

Percebemos pelos dados de modo geral que as interações entre os sujeitos da pesquisa nitidamente aconteciam, no entanto, as interações entre os pares se sobressaíam em quantidades consideravelmente superiores aos demais tipos de interações, e mesmo diante das diversas interrupções destes momentos por parte da professora ou da monitora, com o intuito disciplinar, as crianças resistiam a tais práticas disciplinadoras e brincavam independente desses tipos de ações, construindo, portanto, sua autonomia entre os pares.

As interações entre as crianças eram sempre permeadas por brincadeiras, situações de faz de conta e brinquedos, fossem estes já existentes em sala, que eram poucos e quase inexistentes, ou mesmo os brinquedos construídos pelas crianças a partir de algum outro material, a exemplo da massa de modelar, que era bastante utilizada na prática da professora ou da monitora. Tais atividades lúdicas grande parte das vezes não dirigidas pela professora ou monitora aconteciam sob a égide da organização das próprias crianças, momentos propícios para trocas e que podiam ser percebidos sinais de cooperação, ou seja, dialogavam sobre algo que se propunham a fazer, momentos de ajuda mútua. Pedrosa (1996) explica que a criança quando ainda não domina a linguagem verbal utiliza um conjunto de sistemas (sistema emocional, sistema imitativo e sistema cooperativo) para se comunicar socialmente. Conseguimos perceber nas interações que as crianças utilizaram um ou mais, por vez, dos respectivos sistemas.

Seguidamente, as interações professora ou monitora-criança verificavam-se principalmente nos momentos das atividades pedagógicas que variavam entre momentos dinâmicos, criativos, estimuladores da participação das crianças e práticas escolarizadas em que predominavam a sistematização e a organização. Muito embora fosse sabido que a professora e a monitora possuíam formação específica em educação e demonstrassem uma base de conhecimento relevante, constatamos esta oscilação na prática, na qual em várias situações sobressaía-se o conhecimento popularmente adquirido onde víamos equívocos e até certa insegurança em solucionar situações básicas do cotidiano, bem como sobre as etapas de desenvolvimento das crianças, etapas estas que, quando entendidas, facilitam a compreensão e o cuidado para com as crianças.

O tipo de relação que testemunhamos na maior parte do tempo entre as crianças, a professora e a monitora era mantido em bases afetivas, de diálogo e respeito. Apesar de que 
ainda existiram momentos em que prevalecia a autoridade disciplinadora, foi aparente o respeito mútuo que predominava nas vivências cotidianas. As crianças mesmo pequenas revelavam no comportamento um entendimento evidente do tipo de sentimento, deferência e solicitude edificados gradativamente pela professora e monitora e expressos nas suas ações cotidianas, e, por conseguinte, reprisados pelas crianças.

Cabe ressaltar um fator importante que em grande parte dos casos torna-se obstáculo para uma boa prática, que é uma infraestutura inadequada e desprovida de necessidades básicas para o bom funcionamento de uma creche, o que no caso do nosso campo de pesquisa não era um problema, visto que possuía estrutura física/espacial adequada às especificidades da Educação Infantil. O espaço foi construído de acordo com os padrões exigidos pelos Parâmetros Básicos de Infraestrutura para Instituições de Educação Infantil. Assim, mesmo faltando alguns materiais básicos, este foi consideravelmente um ponto facilitador que assegurou a acessibilidade de todos $\mathrm{e}$ predominantemente das crianças que tinham a possibilidade de locomoção e alcance a praticamente todos os locais da sala, bem como contemplou as necessidades da professora ou da monitora e das crianças, garantindo assim a construção da autonomia principalmente das crianças.

Existia incentivo para que as crianças realizassem boa parte de suas atividades cotidianas sozinhas, mas, quando as crianças sentiam alguma dificuldade ou demoravam a realizar determinada atividade, a professora ou a monitora as faziam pela criança; tais comportamentos eram compartilhados tanto pela professora quanto pela monitora.

Por fim, as interações criança-professora ou monitora eram praticamente baseadas na solicitação de atenção para suprir suas necessidades básicas, o que foi comum visualizarmos. Logo, constatamos que se tratava do tipo de interação mais recorrente direcionadas das crianças para a professora ou monitora, ambas costumavam atender às demandas sem ao menos desafiar ou incentivar as crianças a tentar realizar sozinhas determinadas atividades que pediam, dificultando a conquista de sua autonomia, que poderia ser intensificada.

As interações afetivas eram manifestadas entre todos os sujeitos da pesquisa, mesclando-se entre si, em graus e perspectivas diferenciadas que variavam de acordo com o modo de ser, pensar e agir de cada um. Ainda que professora e monitora dessem demonstrações claras de afetividade durante as interações com as crianças, percebemos, portanto, que mesclavam-se com outros momentos disciplinares e coercitivos, na tentativa de tornar o ambiente silencioso e ordenado. 
| Maria Fabrícia de Medeiros | Adelaide Alves Dias |

A professora e a monitora manifestavam cotidianamente empatia, carinho, afetividade e atenção, no entanto, diante de algumas situações percebemos que havia dificuldade de mediação diante de algum conflito, parecendo-nos ser a opção da imposição sem explicação da situação, para a criança, a melhor saída, contrariando o próprio discurso e até mesmo outras atitudes de ambas em outros momentos perceptivelmente, causando confusão no entendimento das crianças, que em um momento presenciavam uma atitude da professora ou da monitora e em outra situação outro comportamento diferente.

Evidenciando que o professor é antes de tudo um ser humano que tem virtudes, defeitos, necessidades, inseguranças, desejos, e carecem de investimentos. Estes não se reduzem ao financeiro, mas a um conjunto de ações formativas que contemplem as necessidades destes profissionais tão importantes e essenciais para nossa sociedade.

Os resultados da pesquisa indicaram que as interações aconteciam com maior incidência entre as crianças, mesmo estas estando diante de um ambiente desfavorável no tocante às limitações de equipamentos, a recursos didáticos, bem como envoltas de práticas escolarizadas, voltadas para a disciplina. Ainda assim, ficou evidenciado na pesquisa que as crianças resistiam e construíam sua autonomia entre os pares. Corsaro (2011, p. 129) nos lembra de que "características importantes das culturas de pares surgem e são desenvolvidas em consequência das tentativas infantis de dar sentido e, em certa medida, a resistir ao mundo adulto", confirmando, portanto, nossos apontamentos sobre as crianças resistirem às práticas disciplinares.

Com isso, concluímos que as interações afetivas existiam entre todos os sujeitos observados e em situações variadas. No entanto, as interações que influenciavam na autonomia infantil eram as estabelecidas entre os pares: criança-criança, quando estas demonstravam segurança, iniciativas, mais tranquilidade em expressarem-se livremente, disposição em resistir às práticas disciplinadoras que eram submetidas, construindo, portanto, sua autonomia nas relações de pares mesmo sem o incentivo para que estas relações intensificassem. Desta forma é oportuno dizer que encontramos um ambiente com interações intercaladas entre afetivas e proporcionadoras da construção da autonomia (criança-criança) e outras disciplinadoras (professora ou monitora-criança).

\section{REFERÊNCIAS}

BRANCO, Angela Uchôa; PINTO, Raquel Gomes. Práticas de socialização e desenvolvimento na Educação Infantil: contribuições da psicologia sociocultural. Temas em Psicologia, Campinas-SP, v. 17, n. 2, p. 511-525, out. 2009. 
BRASIL. Ministério da Educação e Cultura. Secretaria de Ensino Fundamental. Referencial Curricular Nacional para Educação Infantil. Brasília: MEC, 1998. v. 1, 2 e 3.

BRASIL. Ministério da Educação e Cultura. Secretaria de Educação Básica. Diretrizes Curriculares Nacionais para a Educação Infantil $n^{\circ}$ 01/2009. Brasília: MEC/SEB, 2010.

CORSARO, William A. Sociologia da infância. 2. ed. Porto Alegre: Artmed, 2011.

DE LA TAILLE, Yves. Moral e ética: dimensões intelectuais e afetivas. Porto Alegre: Artmed, 2006.

DIAS, Adelaide Alves. Educação moral para a autonomia na Educação Infantil: o que pensam os professores. Psicologia: Reflexão e Crítica, Porto Alegre, v. 18, n. 3, p. 370 380, 2005.

DIAS, Adelaide Alves; MELO, Marileide Maria de; PIMENTA, Sonia de Almeida; SILVA, Rejane Dias da. Dimensão da afetividade na constituição da profissionalidade docente. In: PIZZI, Laura Cristina Vieira [et.al.] (Org.). Trabalho Docente: tensões e perspectivas. Maceió: EDUFAL, 2012. p. 189-204.

LURIA, A. R. Vigotski. In: VYGOTSKY, Lev. S.; LEONTIEV, A. N.; LURIA, A. R.. Linguagem, Desenvolvimento e Aprendizagem. Trad. Maria da Penha Villalobos. 10. ed. São Paulo: Ícone, 2006. p. 21-37. (Coleção Educação Crítica).

MACÊDO, Lenilda Cordeiro. A infância resiste à pré-escola?. 2014. 232f. Tese (Doutorado em Educação) - Universidade Federal da Paraíba, 2014.

OLIVEIRA, Marta Kohl de. Vygotsky: aprendizado e desenvolvimento, um processo sócio-histórico. 3. ed. São Paulo: Scipione, 1995.

PEDROSA, Maria Isabel; CARVALHO, Ana Maria Almeida. Análise qualitativa de episódios de interação: uma reflexão sobre procedimentos e formas de uso. Psicologia: Reflexão e Crítica, v. 18, n. 3, p. 431-442, 2005.

PEDROSA, Maria Isabel. A emergência de significados entre crianças nos anos iniciais de vida. In: _ (Org.). Investigação da criança em interação social. Recife: Editora da UFPE, 1996. p. 49-68. (Coletâneas da ANPEPP - Associação Nacional de Pesquisa e PósGraduação em Psicologia).

TARDELI, Denise D’ Aurea. O respeito na sala de aula. Petrópolis-RJ: Vozes, 2003.

VASCONCELOS, Cleido Roberto Franchi; AMORIM, Katia de Souza; ANJOS, Adriana Mara dos; FERREIRA, Maria Clotilde Rossetti. A incompletude como virtude: interação de bebê na creche. Psicologia: Reflexão e Crítica, v. 16, n. 2, p. 293-301, 2003.

VYGOTSKY, Lev. S. A formação social da mente. 3. ed. São Paulo: Martins Fontes, 1989.

WALLON, Henri. A evolução psicológica da criança. Trad. Claudia Berliner. São Paulo: Martins Fontes, 2007. (Coleção Psicologia e Pedagogia). 